THURSDAY, JULY 30, 1885

\section{THE UNIVERSITY OF LONDON}

$\mathrm{C}^{\mathrm{s}}$ ONVOCATION met on Tuesday to consider the report and draft scheme submitted to it by Lord Justice Fry's Committee. After a somewhat lengthened debate the House adjourned till November 3, when no doubt their consideration will be resumed.

We do not think much is lost by the delay. As we pointed out last week, the scheme has at first sight an aspert of complexity. But this arises in great measure from the technical form and language with which it is necessary to invest provisions intended to receive legislative effect. We do not think the underlying principles are difficult to disentangle, but it could hardly be expected that such a body as Convocation would grasp them without considerable opportunity for explanation and discussion.

The particular date which the accident of circumstance determined for the meeting was in some respects unfortunate. Many of the medical graduates who might be expected to support the scheme were drawn away by the meeting of the British Medical Association at Cardiff. In November all the medical schools will be in full activity, the leading teachers in every faculty will be in town, and the preliminary ventilation which the scheme has now received, followed, as it will be, by the discussion and reflection of the vacation, will prepare Convocation for a definitive decision in the autumn.

What that decision should be there can hardly be any doubt in the mind of any reasonable person. The remarkable attention bestowed by the leading journals on a purely academic question goes far to prove that the ear of the public is ready to entertain any reasonable proposals for the development of real university work in London. It is for the graduates in Burlington Gardens to decide whether they will approach the task or leave it to some new organisation which may be created for the purpose. That the thing sooner or later in some shape or other will be done we have not ourselves a shadow of a doubt.

The Association for promoting a Teaching University for London has suspended to some extent its own efforts, pending the action of Convocation, to which in its first report it has given its cordial support. The Association and the Committee of Convocation do not, however, seek to attain their objects quite on the same lines, and the identification by some of the speakers on Tuesday of the views put out on behalf of the two perfectly distinct bodies introduced a certain amount of confusion into the debate which no doubt the present opportunity for further consideration will go far to remove.

Of the debate itself little is to be said. Lord Justice Fry's speech explanatory of the scheme had the quality of lucidity which every one expected from him. But more than this, he exhibited a largeness of vicw in contemplating the possible future of the University which might have been expected to carry with it a more enthusiastic sympathy from Convocation than it obtained. The criticisms which followed were mostly on points of

VOL. XXXII.-NO. 822 detail, and, on the whole Convocation, without being adverse, evidently felt that it should like more time for reflection.

THE EVOLUTION OF THE PHANEROGAMS

L'Evolution du Règne Végétal. Les Phanerogames. Par MM. Marion et Saporta. (Bibliothèque Scientifique Internationale, 1885.)

SINCE the appearance of the first volume of this $S$ important work the views of the authors have been subjected to more than one attack, and they have turned aside to vindicate the correctness of their interpretation of the often obscure fossils upon which our knowledge of the earliest forms of plants is based. The wisdom of the delay is unquestionable, for it would have been useless to continue a work whose foundations had been shaken by adverse criticism. It is not to be expected that their views will even yet be universally acceptable, for the difficulties attending the study of fossil plants are such that its most experienced professors are still scarcely agreed upon some of the fundamental questions. It is well known that Prof. Williamson is opposed to the French school as to the gymnospermous nature of several groups of Carboniferous plants, and in addressing the British Association in 1883 (NATURE, September 20, 1884) he criticised in advance some of the main facts dwelt upon in this work. In contrast to the divergent views of English investigators, the greatest workers in France, including the honoured names of the late Adolphe Brongniart, and of MM. Grand'-Eury, B. Renault, Marion, and de Saporta, are in complete accord. Their work presents for the first time a complete outline of the evolution of the vegetable kingdom, and its importance and: novelty are such as to demand a critical as well as friendly examination.

In the former volume it will be remembered (NATURE, May 26, I88 I) the authors endeavoured to trace the development of vegetable life from the protoplasmic body, differentiated from animal life in no way other than through the conversion of a portion of its protoplasm into chlorophyll, to the heterosporous cryptogams. The present volumes prove that there is an almost direct passage from the latter to the far higher phanerogams.

There is no need to argue at the present day that if phanerogams were differentiated from cryptogams this must have taken place in very remote times; and it is equally certain that evolutionists will be disposed to anticipate that the initial differences between them must at first have been relatively imperceptible. An heterosporous cryptogam in which the microspores penetrate to a solitary macrospore in order to effect fertilisation, and in which the prothallus is enclosed and germination takes place in situ, is well on the road to become a phanerogam and, moreover, a gymnospermous one, if the macrosporangium be not protected by any leaf modified into a tegumentum. The change in the reproductive organs was accompanied and preceded by modifications in the vegetative organs, and the transformation is actually found to have progressed through three distinct stages-the progymnospermous, the gymnospermous, and the metagymnospermous.

The Progymnosperms are among the earliest plants 